\title{
EREBEA
}

Revista de Humanidades

y Ciencias Sociales

NúM. 5 (2015), pp. 273-287

ISSN: 0214-0691

\section{El Retablo del Santísimo Cristo de la Columna de la Iglesia Parroquial de San Pedro y San Pablo de Granada. Autoría de Tomás Hermoso y Otras nOtas documentales}

José Antonio Peinado Guzmán

Universidad de Granada

RESUMEN

En el último cuarto del siglo XVIII se va a extender en la retablística española el uso del estuco. Los dictámenes neoclásicos imperantes, unidos a las reales órdenes emanadas desde la Corte, propiciarán la utilización de materiales pétreos nobles, que no siempre podían ser sufragados. Por tanto, este componente menos costoso, venía a conciliar las exigencias normativas con los presupuestos más humildes. Es en este contexto donde debemos situar el retablo del Santísimo Cristo atado a la columna, de la parroquial granadina de San Pedro y San Pablo. Mediante este trabajo, sacamos a la luz datos inéditos de esta obra de Tomás Hermoso, terminada en 1796.

Palabras Clave

Siglo XVIII; Tomás Hermoso; Retablos; Neoclasicismo; Granada.

Fecha de recepción: 8 de mayo de 2015

Fecha de aceptación: 30 de octubre de 2015

\section{Abstract}

In the last quarter of the eighteenth century, the use of stucco in Spanish altarpieces became common. The prevailing neo-classical sensibility, together with actual orders from the Court, fostered the use of stone materials, whose cost could not always be borne. Stucco, a less expensive material, reconciled regulatory demands with the most humble budgets. It is in this context that we must place the Holy Christ tied to a column altarpiece in the Granada parish of San Pedro and San Pablo. In the present article, we cast light on unpublished data dealing with this beautiful altarpiece by Tomás Hermoso, completed in 1796.

\section{KeYwORDS}

The eighteenth century; Tomás Hermoso; Altarpieces; Neoclassicism; Granada. 



\section{INTRODUCCIÓN}

La retablística en la Granada de los últimos años del siglo XVIII estará caracterizada primordialmente por el solapamiento de corrientes artísticas. Por un lado, aún nos encontramos con los estertores del Barroco, cuyas formas eran muy del gusto del pueblo. Frente al mismo se situaban los modelos ilustrados, academicistas y afectos a la élite intelectual que representaban los cánones neoclásicos ${ }^{1}$.

Muchos retablos quedaban todavía por erigirse, tanto en la ciudad como en los pueblos, en el declive de la centuria Setecentista por el entorno granadino. Esa dicotomía de estilos muestra, indirectamente, y como trasfondo, la crítica que por aquel entonces se estaba realizando hacia las trazas barrocas, consideradas imperfectas y poco adecuadas ${ }^{2}$.

En este sentido, no podemos olvidar, en primer lugar, los comentarios detractores de Antonio Ponz al respecto. En su obra Viaje de España, realiza un juicio bastante pormenorizado y negativo de este estilo en lo referente a sus aspectos formales ${ }^{3}$. La reprobación ilustrada tendrá también su continuación en las apreciaciones despectivas del Marqués de Ureña, tales como: "Si miramos a sus altares o a su adorno, ¡Qué deformidad en los retablos! ¡Qué relumbrones tan vacíos! ¡Qué frivolidades tan ajenas a la seriedad del templo!”’ Y Y es que, unido a esa consideración crítica de aquellas formas, siguiendo los postulados ilustrados del "Siglo de las Luces" de iluminar la ignorancia, se pretende un talante netamente didáctico y formativo de orientación estética hacia los elementos clasicistas ${ }^{5}$. Y para ello, como sostenía Claude Bedat, se debería mejorar la formación artística de los artesanos, ya que por éstos el barroco se seguía propagando ${ }^{6}$.

1 J. J. López-Guadalupe Muñoz, "Del Barroco avanzado al Neoclasicismo en la retablística granadina del setecientos: apuntes para una monografía", en Cuadernos de Arte de la Universidad de Granada, 29 (1998), p. 101.

2 E. Guillén Marcos, De la Ilustración al Historicismo: arquitectura religiosa en el arzobispado de Granada (1773-1868). Granada: Diputación Provincial de Granada, 1990, pp. 85-86.

3 A. Ponz, Viage de España: en que se da noticia de las cosas mas apreciables, y dignas de saberse, que hay en ella. Madrid: Viuda de Joaquín Ibarra, 1794.

4 Marqués de Ureńa, Reflexiones sobre la arquitectura, ornato y música del templo; contra los procedimientos arbitrarios sin consulta de la Escritura Santa, de la disciplina rigurosa, y de la crítica facultativa. Madrid: Joaquín Ibarra, 1785, p. 16.

5 Marqués de Ureña, Reflexiones sobre la arquitectura..., p. 99.

6 E. Guillén Marcos, De la Ilustración..., p. 87. 
Otro factor a tener en cuenta y que no puede pasar desapercibido fue la ordenanza de Floridablanca de 25 de noviembre de 1777, por la que se regulaba la construcción de retablos, dictaminando los materiales que se debían usar en la erección de los mismos. A raíz del incendio de la Basílica de Covadonga en ese año, se prohibirá el uso de la madera en los exornos de iglesias y templos, determinándose la utilización de componentes pétreos ${ }^{7}$. Si bien las razones de esta disposición respondían a cuestiones de seguridad de los propios recintos sacros, a la par, y de forma indirecta, se pretendía asestar el golpe definitivo a la retablística barroca ${ }^{8}$.

Según lo dicho, los artistas más señeros que nos vamos a encontrar en Granada trabajando en los diferentes retablos son Francisco Vallejo, Domingo Thomas, Francisco Romero, los hermanos Villoslada, los Salmerón', Francisco Aguado y Jaime Folch o Juan Adán, destacables por sus relieves escultóricos. Todos estos artistas estarán ya imbuidos de los cánones academicistas y del clasicismo imperante. Haciendo un elenco de las obras más importantes de las últimas dos décadas del siglo XVIII granadino, deberíamos citar, en primer lugar, los últimos retablos de la catedral: el de la capilla de San Cecilio, el de la Virgen del Pilar y el de la de San Miguel. El primero de ellos fue diseñado por el citado Francisco Aguado, observándose en el mismo, esculturas de Miguel Verdiguier. Las obras se prolongaron de 1779 a $1787^{10}$. En palabras del prof. Sánchez-Mesa, un ejemplo de lo que él denominaba como "barroco atemperado"11. El retablo de la Virgen del Pilar también es obra de Francisco Aguado, siendo realizado entre 1782 y 1785. El relieve central lo esculpió Juan Adán ${ }^{12}$. Finalmente, el retablo de la capilla de

7 El propio arzobispo D. Antonio Jorge y Galván, se hace eco de esa circular y escribe una carta a su clero, informando del asunto a finales de noviembre de 1777. En: A. C. Gr., Legajo 6-318-14.

8 J. J. Martín González, "Problemática del retablo bajo Carlos III", en Fragmentos, 12-14 (1988), pp. 33-43; J. J. Martín González, "Comentarios sobre la aplicación de la Reales Órdenes de 1777 en lo referente al mobiliario de los templos", en Boletín del Seminario de Estudios de Arte y Arqueología, tomo 58 (1992), pp. 489-496; J. Ma Sánchez Sánchez, "La Real Orden de Carlos III de 1777 y la implantación de los retablo de estuco en el arzobispado hispalense", en Archivo hispalense. Revista histórica, literaria y artística, 2a época, tomo LXXIX, no 240 (1996), pp. 123-125.

9 Esta familia es el máximo exponente de la retablística barroca tardía en Granada, adoptando levemente trazas clasicistas.

10 A. Gallego y Burín, Granada. Guía artística e histórica de la ciudad. Granada: Editorial Don Quijote, 1982, p. 374; M. Gómez Moreno, Guía de Granada. Granada: Imprenta de Indalecio Ventura, 1892, p. 273; J. J. López-Guadalupe Muñoz, "La catedral vestida: la arquitectura de retablos", en L. Gila Medina (coord.): El libro de la Catedral de Granada. Granada: Cabildo Metropolitano de la Catedral de Granada, 2005, pp. 530-532.

11 D. Sánchez-Mesa Martín, "Sobre los tres retablos de la capilla de San Cecilio de la Catedral de Granada y el barroco atemperado. Puntualizaciones estilísticas y documentación (1774-1787)”, en Cuadernos de Arte de la Universidad de Granada, 23 (1992), pp. 269-296.

12 A. Gallego y Burín, Granada. Guía artística..., p. 371; M. Gómez Moreno, Guía de Granada..., p. 270; J. J. López-Guadalupe Muñoz, “La catedral vestida...”, pp. 532-533. 
San Miguel, un proyecto de Francisco Romero de Aragón de 1792, en el que trabajaron Juan Adán y Manuel González en la escultura ${ }^{13}$.

Independientemente de estas tres grandes obras, hemos de referir también otras como el retablo mayor de la iglesia parroquial de San José, que fue diseñado por Ventura Rodríguez y ejecutado por Francisco Vallejo en 1787, trabajando también en los relieves el escultor Jaime Folch ${ }^{14}$; de igual manera, los mismos protagonistas, Vallejo y Folch, los encontramos en la realización del retablo de la capilla de Ánimas del templo imperial de San Matías, una traza dibujada por Domingo Thomas en 1794. El Crucificado del citado espacio será obra del propio Folch ${ }^{15}$.

Fuera ya de la ciudad, hemos de citar el retablo mayor de la iglesia parroquial de Nívar, una obra de Eugenio Valdés realizada unos años antes, concretamente entre 1781 y $1786^{16}$. Asimismo, de material pétreo encontraremos algunos altares laterales ejecutados en localidades como Santa Fe, Montefrío, Murtas o el citado Nivar, a modo de altares laterales ${ }^{17}$. Todos estos van a seguir claramente el estilo neoclásico, siguiendo miméticamente las directrices que aconsejaba el Marqués de Ureña en su diseño: la representación del santo o imagen en cuestión coronada por una cornisa, sostenida de dos o cuatro columnas y terminado con un frontón ${ }^{18}$.

Paralelamente a esto, por la provincia se extenderá la construcción de tabernáculos para las capillas mayores. Esta forma se va a erigir como el elemento decorativo más adecuado, en detrimento de los retablos. Su vinculación con reminiscencias veterotestamentarias, unidas a su carácter simbólico, serán motivo de reflexión por parte de intelectuales ilustrados como Francisco Martínez, el referido Marqués de Ureña o Benito Bails ${ }^{19}$. La influencia de las mismas hará que se considere no como una parte importante, sino la más indispensable dentro del exorno de los templos. Muestras de esta tipología las vamos a contemplar

13 J. J. López-Guadalupe Muñoz, “La catedral vestida...”, pp. 533-536.

14 A. Gallego y Burín, Granada. Guía artística..., p. 540; M. Gómez Moreno, Guía de Granada..., p. 458; E. Guillén Marcos, De la Ilustración..., pp. 87-88.

15 A. Gallego y Burín, Granada. Guía artística..., p. 207; E. Guillén Marcos, De la Ilustración..., pp. 88-89. Una síntesis sobre la obra retablística de la Granada del último cuarto del siglo XVIII y de sus autores la encontramos en: J. J. López-Guadalupe Muñoz, "Del Barroco avanzado...”, pp. 101-103. El citado Jaime Folch, a pesar de ser de formación académica, también atendió demandas de corte barroco, tales como los Nazarenos de Gádor (Almería) y Restábal (Granada), ambos desaparecidos.

16 J. J. López-Guadalupe Muñoz, "La catedral vestida...”, p. 533.

17 E. Guillén Marcos, De la Ilustración..., p. 91.

18 Marqués de Ureña, Reflexiones sobre arquitectura..., p. 279.

19 F. Martínez, Introducción al conocimiento de las Bellas Artes o diccionario manual... Madrid: Viuda de Escribano, 1788, p. 320; B. Bails, Diccionario de arquitectura civil. Madrid: Imprenta de la Viuda de Ibarra, 1802; Marqués de Ureńa, Reflexiones sobre arquitectura..., p. 154. 
en pueblos como Santa Fe, Montefrío, Vélez Benaudalla, Algarinejo, Murtas o Albuñol ${ }^{20}$. Incluso la propia catedral se vio contagiada de esta moda. Un diseño de Francisco Romero de Aragón, encargado en 1791, terminará viendo la luz en $1804^{21}$. Aquel tabernáculo, muy simple y realizado en madera por Francisco Villanueva, iba a ser una solución provisional para un proyecto de mayor envergadura, que nunca sería realizado, y que finalmente sería sustituido más de cien años después por la obra de Navas Parejo que hoy contemplamos en la Capilla Mayor. Otro tabernáculo de enorme interés es el que se hizo para la parroquial de San Pedro y San Pablo de la capital. El mismo se ejecutó para sustituir al que se trajo de la catedral en el verano de 1614, una obra que fuera de Diego de Siloe ${ }^{22}$. El que se construirá lo hará Francisco Vallejo en 1790, participando en la escultura Jaime Folch. El diseño del mismo probablemente lo trazó Domingo Thomas ${ }^{23}$. Finalmente, también tenemos que hacer mención como trabajos del mismo autor, a los tabernáculos de la iglesia de la Magdalena y el del desaparecido templo de Santa Escolástica ${ }^{24}$.

Para concluir esta introducción, no debemos olvidar un pequeño detalle que va a condicionar las decoraciones de las diferentes iglesias: las posibilidades económicas, o mejor dicho, la limitación de las mismas. Los postulados clasicistas que abogaban por el uso de la piedra o los mármoles, no siempre podían ser financiados por las localidades, municipios o templos de escasos recursos. Ante esta situación comenzaría a extenderse el recurso del estuco policromado. En palabras del prof. Martín González: "la cuestión económica es la que a la postre prevalecía" 25. Mediante la utilización del mismo como elemento cubriente, y notoriamente más barato en su costo, se imitaba a la perfección el resultado final de las obras hechas con materiales más nobles. No es de extrañar, pues, que apareciesen libros como el del canónigo racionero de la catedral de Ciudad Rodrigo, donde se exponía y explicaba el método o forma de ejecutar la labor del estuco ${ }^{26}$. Y es que precisamente, Tomás Hermoso, artista del que vamos a tratar, trabajó esta técnica en los retablos y altares que realizó, primordialmente porque los encargos que recibiera eran bastante secundarios, y probablemente carentes de altos presupuestos.

20 E. Guillén Marcos, De la Ilustración..., pp. 92-93.

21 J. A. Peinado Guzmán, "El tabernáculo de la Catedral de Granada: de Diego de Siloe a Navas Parejo", en Cuadernos de Arte de la Universidad de Granada, 41 (2010), p. 54.

22 J. A. Peinado Guzmán, "El tabernáculo...", p. 49.

23 E. Guillén Marcos, De la Ilustración..., pp. 93-95; J. J. López-Guadalupe Muñoz, "La catedral vestida...”, p. 535.

24 E. Guillén Marcos, De la Ilustración..., pp. 93 y 95.

25 J. J. Martín González, "Problemática del retablo...”, p. 42; J. Ma Sánchez Sánchez, "La Real Orden de Carlos III...", pp. 123-127.

26 R. Pascual Díez, Arte de hacer estuco jaspeado o de imitar los jaspes a poco coste y con la mayor propiedad. Madrid: Imprenta Real, 1785. 
El Retablo del Santísimo Cristo de la Columna de la Iglesia de San Pedro y San Pablo de Granada.

El templo parroquial de San Pedro y San Pablo, ubicado en la parte baja del Albaycín, en la histórica y castiza Carrera del Darro granadina, fue construido sobre una antigua mezquita. En 1559 sería derribado aquel edificio para levantar la actual iglesia bajo trazas, parece ser, que de Juan de Maeda. Quedó concluido en $1567^{27}$. Dentro de los diferentes espacios que componen este templo con planta de cruz latina, se encuentra uno de las más destacados, el altar del Santísimo Cristo de la columna, ubicado en el lateral del brazo izquierdo del crucero. En él se veneraba un lienzo de dicha advocación. Posiblemente sea el que Gallego y Burín atribuye a Pedro Machuca ${ }^{28}$. Dicho cuadro, en la actualidad no se encuentra ya ubicado en dicho altar, habiéndose trasladado, según parece, a la capilla que aloja la entrada lateral del templo. Dicho esto, el citado espacio que tratamos, a finales del siglo XVIII, pertenecía, según la documentación encontrada ${ }^{29}$, a dońa María Antonia Carnero, natural de Andújar, tal y como reseńa su apoderado, don Salvador Echeverría. Con fecha de 23 de diciembre de 1793 se declara que en la mencionada capilla se hallaba una reja que, por razones estéticas, se decide retirar puesto "que causava diformidad al buen aspecto de su ermoso edificio"30. Tras el mandato de la Real Cámara de Castilla de adornar y reparar el templo, se retiró la mencionada reja, quedándose la misma depositada en la iglesia. A continuación se solicita permiso para ser vendida, realizándose la venta y siendo tasada en 4237 reales con 32 maravedís.

Una vez acontecido esto, según se desprende de la documentación consultada, se decide erigir un retablo de estuco en aquel espacio para adecentarlo mejor. Del recibo adjunto que se conserva, se sabe que de la cantidad anteriormente referida se destinaron 4000 reales a tal efecto.

27 F. de P. Valladar, Guía de Granada. Granada: Imp. y Lib. De la Viuda e Hijos de P. V. Sabatel, pp. 332-333; M. Gómez Moreno, Guía de Granada..., pp. 423-426. A. Gallego y Burín, Granada. Guía artística..., pp. 350-352.

28 A. Gallego y Burín, Granada. Guía artística..., p. 352. En la reciente exposición celebrada en el Palacio de los Condes de Gabia (Granada) denominada Iuxta Crucem (5 de marzo-17 de mayo de 2015), dicho lienzo se atribuye a un seguidor de Pedro Campaña.

29 En la actualidad los archivos de las parroquias de San Pedro y San Pablo y los de San Juan de los Reyes se encuentran ubicados en las dependencias de la primera parroquial. Paradójicamente, la documentación encontrada sobre el retablo que trabajamos no se hallaba en las cajas de San Pedro y San Pablo, sino en las de San Juan de los Reyes.

30 Archivo Parroquial de San Juan de los Reyes, Legajo Fundaciones, no 1, pza. s/n, Licencia, consentimiento, venta de la reja de la capilla del Señor amarrado a la coluna del Señor Carnero, y su importo convertido en un nuevo retablo, y quentas de su costo, con el produto del valor de dicha reja. Año 1796. 


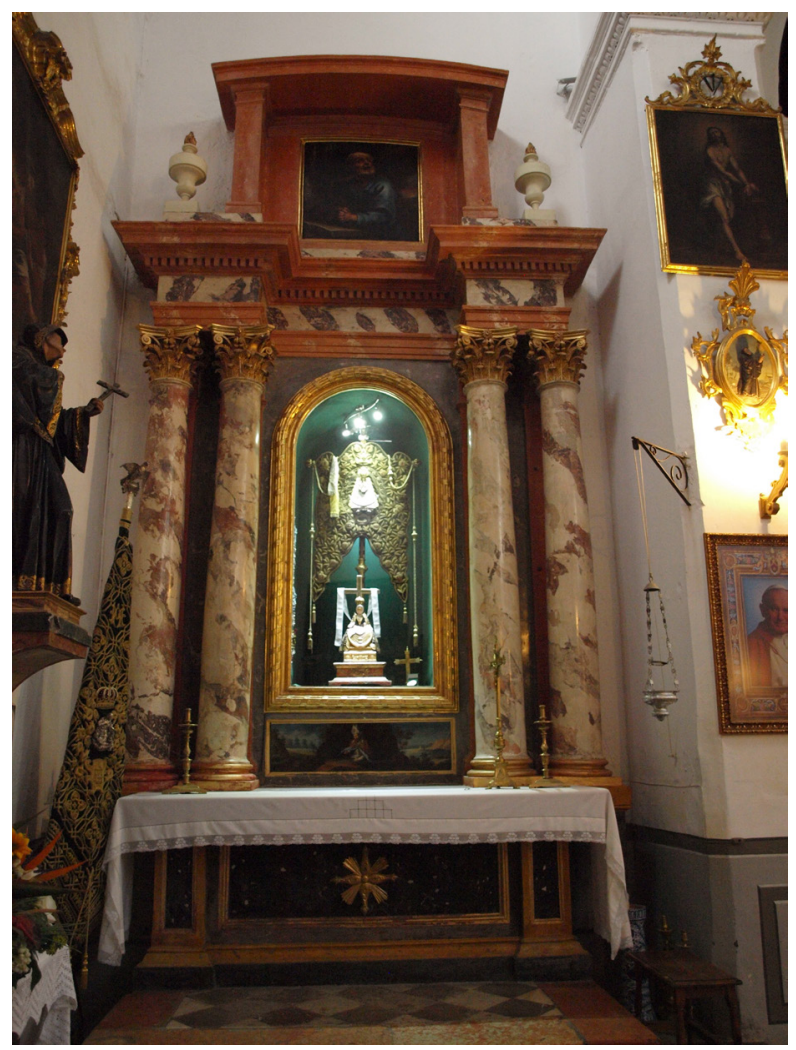

Figura 1. Retablo del Santísimo Cristo de la Columna. Iglesia de San Pedro y San Pablo (Granada). Tomás Hermoso, 1796. Foto: José A. Peinado Guzmán [JAPG]

Dicho esto, con fecha de 14 de mayo de 1795 el "artífice de construir estucos", Tomás Hermoso, en la nota del contrato especifica una serie de datos. En primer lugar, que el diseño del retablo había sido aprobado por la Academia. Seguidamente, se nos indica el lugar de ubicación del mismo: la capilla lateral del lado del Evangelio de la parroquial de San Pedro y San Pablo. En él irán colocados tres lienzos con sus respectivos marcos dorados: uno de San Pedro para el ático; el central y principal sería el de "Nuestro Señor" (Cristo atado a la columna); y finalmente el de San Cecilio, debajo del anterior. A continuación describe la propia obra: un retablo de estuco, de orden corintio, con cuatro columnas, su respectiva mesa de altar con frontal, rematándose con su correspondiente ático. Asimismo, las basas, capiteles de las columnas, los filetes y las medias cañas del frontal irían decoradas en dorado. Finalmente, se compromete a tener concluido su trabajo para el mes de mayo de 1796. 


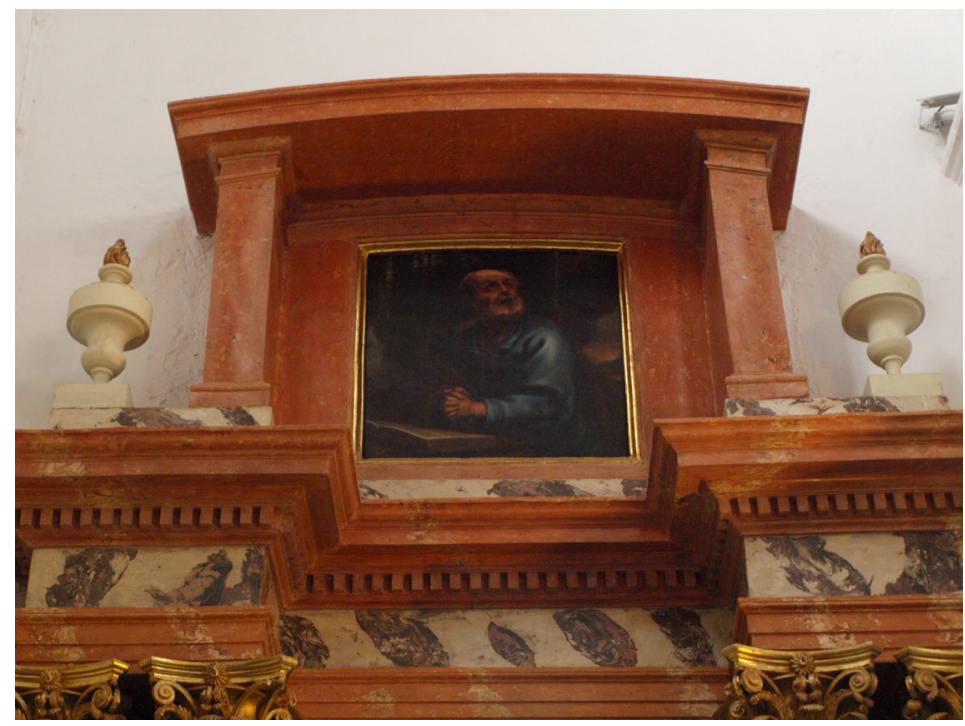

Fig. 2. Retablo del Santísimo Cristo de la Columna. Iglesia de San Pedro y San Pablo (Granada). Tomás Hermoso, 1796. Detalle del cuadro de San Pedro arrepentido. Foto: [JAPG].

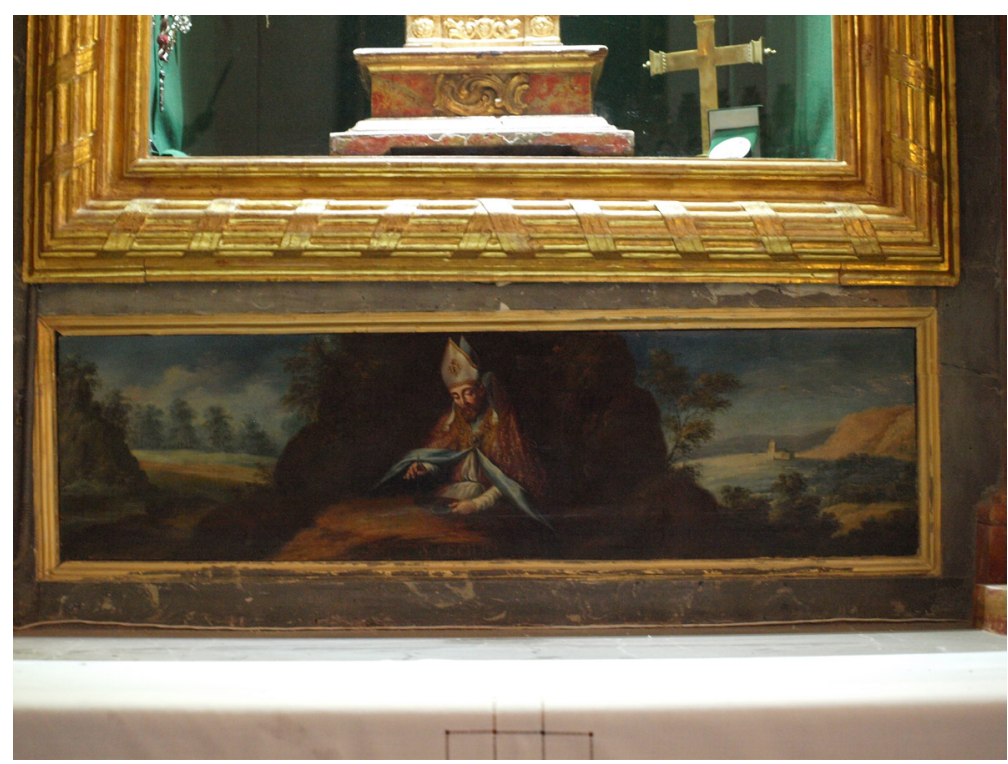

Figura 3. Retablo del Santísimo Cristo de la Columna. Iglesia de San Pedro y San Pablo (Granada). Tomás Hermoso, 1796. Detalle del lienzo de San Cecilio. Foto: [JAPG] 
Una vez comenzadas las obras, parece que tuvieron cierto retraso en su conclusión, algo por otro lado previsto, debido a las continuas lluvias y la humedad. Este hecho lo acredita el propio retablista Tomás Hermoso, quien en el recibo de la citada cantidad que le da el Beneficiado de la parroquia don Carlos de Torres, testimonia que, como se había comprometido en mayo de 1795, había de terminar su trabajo. Y que el mismo no había podido continuarse por esas razones meteorológicas. El documento se firma en 22 de marzo de 1796. A esta fecha quedaba únicamente por concluir el ático y el dorado del retablo. A modo anecdótico da la sensación, por las frases finales del texto, que el cura de la parroquial de San Pedro y San Pablo pagó todo el importe, como forma de presión moral para con el artista.

Así pues, y según lo dicho, el retablo del Santísimo Cristo atado a la columna se corresponde con el que hoy alberga el simpecado de la Hermandad de la Virgen del Rocío. El mismo, como ya se ha referido, se halla en el crucero del templo, en el lado del Evangelio. Se trata de una obra de sección recta en su planta, compuesto en alzado por un solo cuerpo rematado por su correspondiente ático. La mesa de altar posee un frontal con rectángulo central enmarcado por pilastras, todo ello decorado a base de molduras doradas, y centrado por una cruz con ráfagas de similar tonalidad. Sobre la mesa de altar, directamente se alzan cuatro columnas de orden corintio, dada la inexistencia de banco en este retablo. Las mismas, pareadas, flanquean a sendos lados la hornacina central. Poseen fuste liso, imitando el mármol travertino veteado en tonos marrones. Tanto las basas como los capiteles se policroman en tonalidad dorada. Detrás, y adosadas al muro, quedan las respectivas retropilastras entonadas en imitación de mármol rojo. Sobre las columnas divisamos el entablamento, compuesto por su arquitrabe con sus correspondientes tres platabandas de tonalidad rojiza. Encima de éstas observamos el friso liso, de similar color que las columnas. El cuerpo se culmina con la cornisa que, en la parte inferior, se decora con una línea continua de gotas. El único cuerpo del retablo queda centrado por la hornacina del titular. Posee la clásica puerta de cristal con forma de arco de medio punto, decorada con moldura dorada. En el interior de la misma se alberga el simpecado de la Hermandad de la Virgen del Rocío. La iluminación del espacio, realizada mediante un plafón de cuarto de baño muestra, a todas luces, lo inapropiado de dicha solución. Debajo de la hornacina central, y justo encima de la mesa de altar, se aloja una pintura sobre lienzo de formato apaisado, representando a San Cecilio sedente en un paraje natural. La misma constituye una obra anónima granadina del siglo XVIII.

El ático, finalmente, conforma un espacio cuadrangular enmarcado por dos pilares adosados o pilastras de orden dórico, cerrándose por una cubierta curva amoldurada. Todo ello policromado en tonos marmóreos rojizos. El centro de este ático se ocupa por una pintura anónima de San Pedro arrepentido, iconografía evidentemente relacionada con el momento de la Flagelación de Cristo, a quien 
está dedicado el altar. Sería también una obra anónima granadina del siglo XVIII.

Una vez concluida la descripción del retablo, se ha de hacer referencia, para terminar, a otros detalles menores que se han encontrado en la documentación consultada acerca del exorno del mismo. Concretamente nos referimos a la compra de una lámpara de azofar con su lamparín y un par de candeleros de hojalata, por valor de 120 reales de vellón, así como algún que otro arreglo inferior.

\section{Conclusión}

Dado lo tardío de la construcción del retablo del Santísimo Cristo atado a la columna, terminado en 1796, nos da muestra también de lo que supusieron los retablos de estuco en la archidiócesis granadina. En primer lugar, esta tipología concreta no es muy abundante, no alcanzan siquiera ni una veintena, encontrándose los mismos en localidades o municipios de importancia secundaria ${ }^{31}$. Los mismos suponen la finalización del exorno retablístico en Granada y provincia. Las formas neoclásicas suponen el aterrizaje suave de la ornamentación de los espacios sagrados y, concretamente, la realización de los mismos mediante el estuco, indican la pobreza de estos, así como la escasez de presupuesto para su construcción. Tomás Hermoso, artista académico que creemos trabajó para el arzobispado de Granada de forma habitual, conocemos que también realizó otras obras para el mismo. De hecho, consideramos que el altar de la Virgen de la Buena Dicha, que se ubica en la misma parroquial de San Pedro y San Pablo, en el lado opuesto al que se encuentra el que hemos descrito en el crucero, sería igualmente obra del citado Hermoso, ya que supone una copia mimética del retablo del Santísimo Cristo de la Columna. Asimismo, también son de su factura los altares y tabernáculo de la iglesia parroquial de Ohanes (Almería) ${ }^{32}$, así como la capilla del Convento de la Encarnación en la capital, unas trazas de $1795^{33}$.

31 Según ha estudiado el prof. López-Guadalupe, sobre el reconocimiento de bienes que hiciera Fernández Bravo hacia 1755, los retablos de yeso que se diseminan por el arzobispado de Granada serían los siguientes: en Pórtugos hay uno; en Melegís habría cuatro; en Murchas, otro más; en Nigüelas hay dos; en Alfacar, uno; en Cogollos Vega habría cuatro; en Gójar, tres; y, finalmente, en Nívar habría uno. J. J. López-Guadalupe Muñoz, "Arquitectura religiosa y mobiliario litúrgico en la diócesis de Granada a mediados del siglo XVIII”, en M. L. López-Guadalupe Muñoz y A. L. Cortés Peña (coords.): Estudios sobre Iglesia y sociedad en Andalucía en la Edad Moderna. Granada: Universidad de Granada, 1999, pp. 479-486.

32 E. Guillén Marcos, De la Ilustración..., p. 93.

33 A. Gallego y Burín, Granada. Guía artística..., p. 281. 


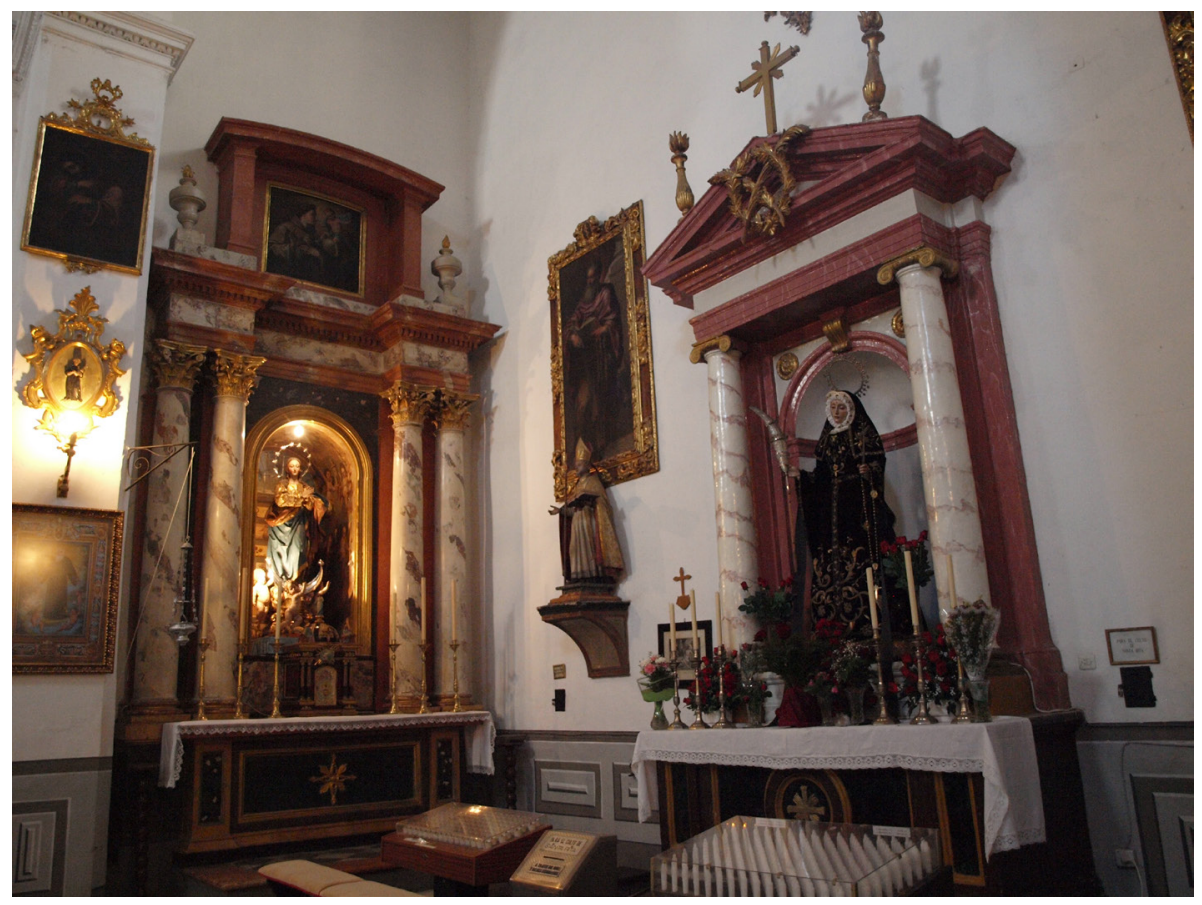

Figura 4. Retablo de la Virgen de la Buena Dicha. Iglesia de San Pedro y San Pablo (Granada). Atribución a Tomás Hermoso, c. 1796. Foto: [JAPG]. 


\section{ApÉNDICE DOCUMENTAL}

Archivo Parroquial de San Juan de los Reyes, Legajo Fundaciones, no 1, pza. s/n, Licencia, consentimiento, venta de la reja de la capilla del Señor amarrado a la coluna del Señor Carnero, y su importo convertido en un nuevo retablo, y quentas de su costo, con el produto del valor de dicha reja. Año 1796.

"Capilla del Santísimo Christo de la Coluna. fol. ro

Granada 23 de diziembre de 1793.

Señor Provisor

Don Salvador Echeverria vezino de esta ciudad apoderado de la Señora doña María Antonia Carnero que lo es de la de Andújar a la obediencia de Vuestra Señoría dice que entre las posesiones y patronatos de los mayorazgos que goza dicha señora, es una capilla en la parroquial de San Pedro y San Pablo la qual tenía una reja que causava diformidad al buen aspecto de su ermoso edificio, y haviendose mandado por la Real Camara de Castilla reparar y adornar este templo, de acuerdo con sus ministros titulares y el comisionado, se quitó la referida reja y se halla depositada en la misma yglesia; $y$ deseando ${ }^{\text {fol }} r^{\circ} / \mathrm{mi}$ parte que su importe se imbierta en adorno de la propia capilla de que es patrona, pues se halla indecente. Suplica a Vuestra Señoría conceder su licencia para la venta de la reja de que ha hecho mención para el expresado fin, la que se ejecute y la imbersion de la cantidad que produzca con interbencion de los ministros titulares y del que representa como apoderado de la señora proveedora formando cuenta de uno y otro firmado por los expresados la que se coloque en el archivo de la citada yglesia en que recivire merced. Granada y diciembre 20 de 1793.

Salbador Echeverria [rúbrica] fol. v ${ }^{\circ}$ ".

"Tengo en mi poder el inporte de la reja del Santísimo Christo, que se vendio por orden de su patrono, y dueño de su capilla en quatro mil doscientos y treinta y siete reales con treinta y dos maravedis - 4237,32.

Juan Vicente de Salazar [rúbrica]

Carlos de Torres Diez de Garay [rúbrica]

Tengo gastado de la dicha cantidad cinquenta

y dos reales costo de pagar la dicha reja $52 r$

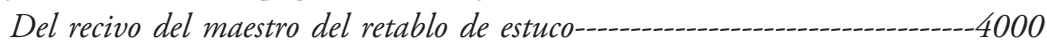

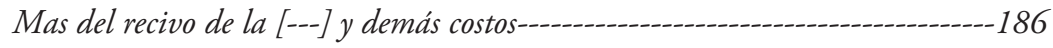

Dn. Carlos de Torres [rúbrica]

V. B. Juan Vicente de Salazar [rúbrica]". 
"Recebi del Sr. D. Carlos de Torres Beneficiado de la yglesia parroquial de San Pedro y San Pablo de esta ciudad quatro mil reales vellón, que es la misma cantidad en que contrate la construccion de un nuebo retablo de estuco para la capilla del lado del evangelio de la misma yglesia previniéndose que por rrazon del presente tiempo de aguas y umeda no se a concluido el dorado y atico de dicho retablo que queda de mi cargo egecutarlo y de estar perfectamente echo en todas sus partes como me oblige en el mes de mayo de mil setecientos noventa y cinco, constara a continuacion de este recibo por declaración de uno de los directores de esta dicha ciudad por averseme entregado el todo del dinero es por favor que me a hecho dicho señor beneficiado, Granada veinte y dos de marzo de mil setecientos noventa y seis.

Son 4000 reales de vellon.

Tomás Hermoso [rúbrica]

V. B. Juan Vicente Salazar [rúbrica]”.

"Digo yo D. Tomás Hermoso, artifice de construir estucos, que habiendo precedido aprobación de la Academia desta ciudad, del diseño formado para un retablo en el altar de la Capilla lateral en el lado del Evangelio de la parroquial de San Pedro y San Pablo desta ciudad, en donde esta colocada una pintura de Nuestro Señor, otra de San Cecilio, y otra de San Pedro, la primera de estatura natural, he contratado con los señores ministros titulares de la propia yglesia ejecutar un nuebo retablo de estuco para la espresada capilla, el que a de ser de orden corintio, con quatro columnas, con su mesa de altar, frontal de la misma materia, y su colocación un atico, en el qual se a de colocar el lienzo de san Pedro, en el medio el del Señor, y bajo de este el de san Cecilio, todos tres con sus marcos dorados, y lo mismo las basas, y capiteles de las columnas, y los filetes, y medias cañas del frontal, todo en la cantidad de quatro mil reales y el antiguo, y viejo adorno, o retablo en donde estaban colocadas las citadas pinturas, a lo qual me obligo en toda forma, y dar concluida dicha obra en el mes de mayo del año que viene de mil setezientos noventa y seis: y para que a ello se me pueda obligar formo el presente que firmo en Granada a catorce de mayo de mil setezientos noventa y cinco, siendo testigos el señor D. Ysidro Cienfuegos, contador general de yglesias de este Arzobispado, D. Marcos Carmona y D. Estevan de Borja, sachristan en dicha yglesia.

Tomás Hermoso. [rúbrica]”.

"Digo yo Francisco Ruiz maestro de almirecero de esta ciudad de Granada que e rrecevido de el señor D. Carlos de Torres Diez de Lara Beneficiado de la yglesia parroquial de San Pedro y San Pablo de dicha ciudad \#ciento veinte reales de vellon\# balor de una lámpara de azofarcon su platillo de oja de lata, con su vidrio o lamparin, y un par de candeleros de dicho metal, todo nuevo para el culto de la capilla del Señor de la Coluna que se venera en la expresada yglesia haviendome dicho señor Beneficiado entregado la lámpara vieja del referido metal que avia en la referida capilla y tomado a quenta de lo que nuevo tengo entregado, y para su abono doy el presente que firmo en 
dich a ciudad a veinte y uno de marzo de mil setecientos noventa seis años = Francisco Ruiz [rúbrica]

Ytem 6 reales de olandilla morada para un velo al señor en semana santa. Costó con el galón y echuras 58 reales de vellón.

Ytem de quitar el hierro viejo de la lámpara y poner uno nuebo. Costó ocho reales de vellón.

Importa todo 186 reales de vellón.

Como sacristán de dicha yglesia e rrecevido todo lo contenido arriba $=$ Visto. $D$. Estevan de Borja [rúbrica].

V. B. Juan Vicente de Salazar [rúbrica]". 
